\title{
BMJ Open Systematic review to identify proxy indicators to quantify the impact of eHealth tools on maternal and neonatal health outcomes in low-income and middle-income countries including Delphi consensus
}

\author{
Caroline Perrin, Lothaire Hounga, Antoine Geissbuhler
}

To cite: Perrin C, Hounga L, Geissbuhler A. Systematic review to identify proxy indicators to quantify the impact of eHealth tools on maternal and neonatal health outcomes in low-income and middleincome countries including Delphi consensus. BMJ Open 2018;8:e022262. doi:10.1136/ bmjopen-2018-022262

- Prepublication history for this paper is available online To view these files, please visit the journal online (http://dx.doi. org/10.1136/bmjopen-2017022262).

Received 12 February 2018 Revised 18 June 2018 Accepted 26 July 2018
Check for updates

(C) Author(s) (or their employer(s)) 2018. Re-use permitted under CC BY-NC. No commercial re-use. See rights and permissions. Published by BMJ.

Department of Radiology and Medical Informatics, Faculty of Medicine, University of Geneva Geneva, Switzerland

Correspondence to

Caroline Perrin;

caroline.perrin@hcuge.ch

\section{ABSTRACT}

Objective To identify interventions that could serve as reliable proxy indicators to measure eHealth impact on maternal and neonatal outcomes.

Design Systematic review and Delphi study.

Methods We searched PubMed, Embase and Cochrane from January 1990 to May 2016 for studies and reviews that evaluated interventions aimed at improving maternal/ neonatal health and reducing mortality. Interventions that are not low-income and middle-income context appropriate and that cannot currently be diagnosed, managed or impacted by eHealth (eg, via telemedicine distance diagnostic or e-learning) were excluded. We used the Cochrane risk of bias, Risk Of Bias In Non- randomised Studies - of Interventions and ROBIS tool to assess the risk of bias. A three-step modified Delphi method was added to identify additional proxy indicators and prioritise the results, involving a panel of 13 experts from different regions, representing obstetricians and neonatologists.

Results We included 44 studies and reviews, identifying 40 potential proxy indicators with a positive impact on maternal/neonatal outcomes. The Delphi experts completed and prioritised these, resulting in a list of 77 potential proxy indicators.

Conclusions The proxy indicators propose relevant outcome measures to evaluate if eHealth tools directly affect maternal/neonatal outcomes. Some proxy indicators require mapping to the local context, practices and available resources. The local mapping facilitates the utilisation of the proxy indicators in various contexts while allowing the systematic collection of data from different projects and programmes. Based on the mapping, the same proxy indicator can be used for different contexts, allowing it to measure what is locally and temporally relevant, making the proxy indicator sustainable. PROSPERO registration number CRD42015027351.

\section{INTRODUCTION}

Since 1990, maternal and child mortality have approximately halved; however, most of the remaining deaths are preventable. ${ }^{1}$ Child
Strengths and limitations of this study

- Limitation: some potential proxy indicators may not have been identified in the systematic review for two possible reasons: (1) due to, for example, a very Iow GRADE quality, as for some interventions based on ethical reasons, it is not possible to conduct high-quality randomised studies, or (2) no studies have investigated these as they are standard of care. They may also have been overlooked as unforeseen, for example, disruptive uses of eHealth may emerge and offer unexpected ways to improve practices.

- Strength: to address the limitation of potentially overlooked proxy indicators, the results were assessed and completed in a Delphi consensus process with a group of international experts.

- Strength: a review of this kind, aiming at identifying proxy indicators that could be used to measure the impact of eHealth interventions on maternal and neonatal health outcomes, particularly in low-income and middle-income countries has not yet been conducted.

mortality decreased disproportionately for older children, and neonatal deaths account now for $45 \%$ of under-5 mortality. ${ }^{2}$ Uneven progress between countries and within countries, with prorich and prourban inequalities, leaves women and children in rural areas with insufficient access to quality health care services. ${ }^{1}$

Information and communication technologies (ICTs) can provide innovative approaches for alleviating these inequalities, particularly in rural and isolated settings. They do so by overcoming geographical barriers, increasing access to healthcare services, providing continuing education and enabling collaborative healthcare in remote locations. ${ }^{3-13}$ The WHO 
defines electronic health (eHealth) as the cost-effective and secure use of ICTs for health and health-related fields. ${ }^{14}$ The potential of eHealth on positive therapeutic and clinical outcomes has been repeatedly postulated, but strong evidence is scarce. Although scientific literature offers an increasing number of publications studying the impact of eHealth tools on the quality, safety and cost-effectiveness of health care, there is still a significant gap between the postulated and empirically demonstrated benefits, including therapeutic and clinical outcomes. ${ }^{15-20}$ It is essential to devote more effort to evaluation and to ensure that the methodology adopted is multidisciplinary and thus capable of disentangling the often complex web of factors that may influence the results. It is equally important that existing activities are subject to rigorous, multidisciplinary and independent assessment. Even though low-cost telemedicine applications have proven to be feasible, clinically useful, sustainable and scalable, they are not being adopted on a significant scale due to a variety of barriers, including the absence of robust and general supportive scientific evidence of their impact. ${ }^{15-172122}$

The need for evaluating eHealth impact on patient outcomes has been strongly emphasised..$^{192022-28}$ The main barrier remains in the limited identification of measurable and reliable indicators. ${ }^{29}$ The relevance of these indicators may be context dependent and their extrapolation considerably restricted. Availability of outcome indicators (direct and proxy) will facilitate consistent outcome measurements and comparability of studies. ${ }^{29}$

Health outcomes research established as a mean to evaluate the effectiveness of healthcare interventions and an approach to inform resource allocation. ${ }^{30} 31$ Obstacles for the outcomes evaluation of eHealth tools include the absence of methodologies and indicators. ${ }^{29}$ The identification of indicators is complex as the timespan between intervention and potential outcome (reduction in maternal/neonatal mortality) is long. Due to this duration, the outcome might be influenced by various confounding factors, and it is difficult to attribute the outcome to the eHealth intervention. The use of proxy indicators helps addressing this issue by measuring changes closer to the intervention.

The objective of this review is to identify proxy indicators that can be used in future studies aiming at measuring the impact of eHealth interventions on maternal/neonatal health outcomes in low-income and middle-income countries (LMICs). The review question is: which interventions that can be impacted by eHealth applications have results that can be clearly linked to maternal and neonatal health outcomes in LMIC countries and could therefore serve as reliable proxy indicators?

\section{METHODS}

The review was conducted and reported in line with the standards of the Preferred Reporting Items for Systematic
Reviews and Meta-Analyses (PRISMA) statement. ${ }^{32}$ The review protocol is registered in PROSPERO; the detailed description can be accessed on the platform. ${ }^{33}$ In short, the review identified interventions, which have an alleged impact on maternal/neonatal health, and are suitable for delivery in LMICs to serve as proxy indicators. In this article, previous reviews are included according to the recommendations for integrating existing systematic reviews into new reviews by Robinson et al. ${ }^{34}$

\section{Searching}

To identify studies and reviews that evaluated the effect of interventions on maternal and neonatal health, a comprehensive search of PubMed, Embase and the Cochrane Library was carried out using a combination of text words and controlled vocabulary terms related to the interventions and possible outcome measures. The search strategy was adapted for each database. Studies with an abstract published in English from 1990 to May 2016 were considered for inclusion. The third phase consisted of searching databases of multilateral organisations and Google Scholar.

\section{Inclusion/exclusion criteria}

Randomised controlled trials, quasiexperimental studies, observational studies, systematic reviews and intergovernmental and non-governmental agency reports were considered for this review.

Population: pregnant women at any gestation age, postpartum women up to 6 weeks after giving birth and neonates (up to 28 days after birth).

\section{Intervention}

We included any intervention at health system level aiming at improving maternal/neonatal health and reducing maternal/neonatal mortality.

Type of outcome measures: neonatal outcomes (eg, neonatal mortality, stillbirth, low birth weight and preterm birth) and maternal outcomes (eg, maternal mortality, pre-eclampsia and gestational hypertension).

Studies were excluded if they were not LMIC context appropriate or if the interventions cannot currently be diagnosed, managed or impacted by eHealth interventions, such as telemedicine distance diagnostics or e-learning, as well as qualitative studies and opinion pieces.

\section{Study selection}

One author conducted an initial screening to exclude articles whose titles were obviously irrelevant. Subsequently, two reviewers independently rated titles and abstracts based on relevance to the study objectives. The third reviewer resolved discrepancies in the rating. All studies that were rated potentially relevant or definitely relevant underwent full-text review. For each included study, the authors verified that these were not comprised in the included systematic reviews and if so they were excluded. Figure 1 summarises the study selection. 


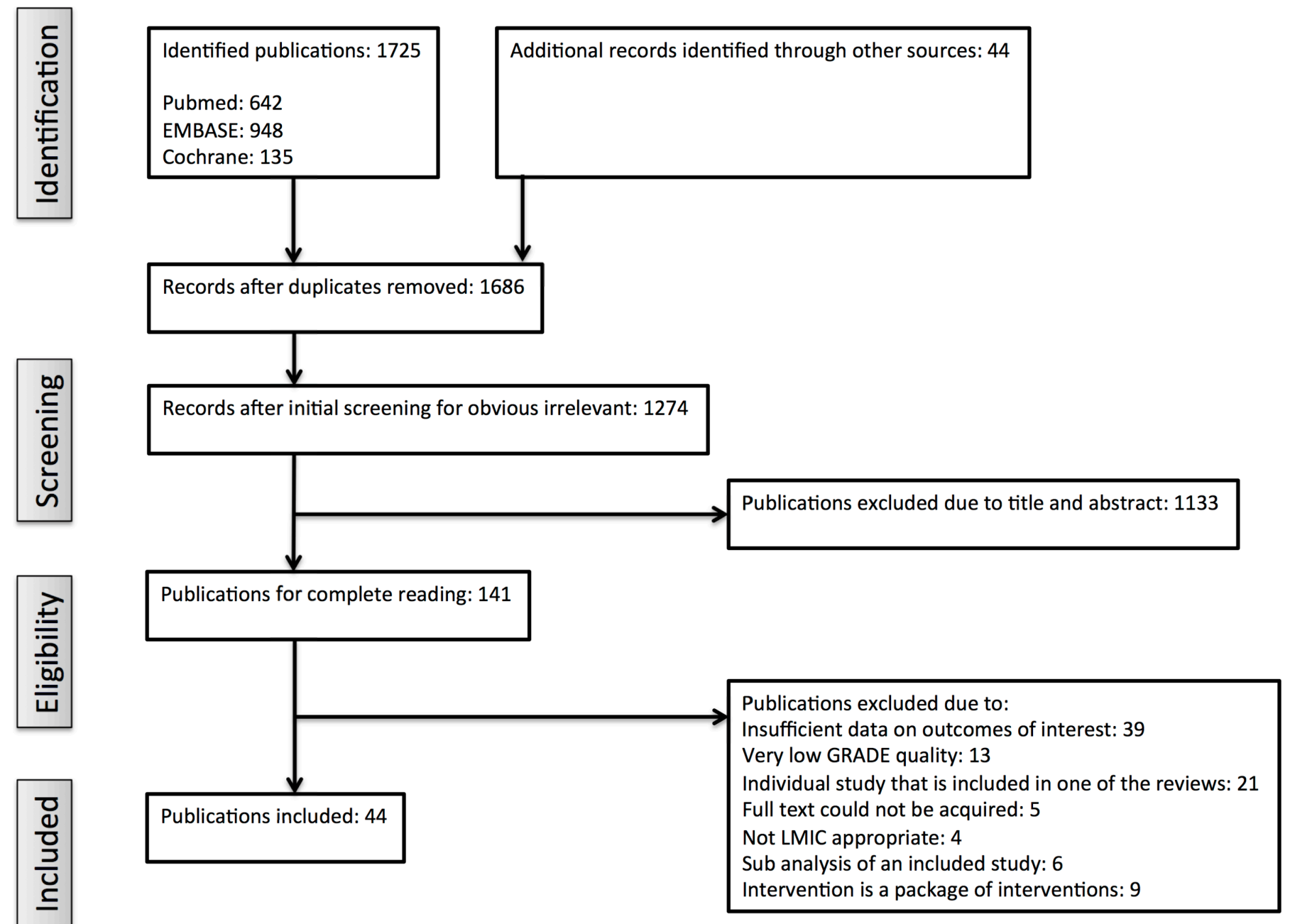

Figure 1 Flow chart of study selection for inclusion in the systematic review. LMIC, low-income and middle-income country.

\section{Data abstraction, quality assessment and data synthesis and analysis}

Study design, setting, study population characteristics, description of the intervention, outcomes measured and effects of studies, which were assessed as eligible, were abstracted by one author into a standardised spreadsheet and were thoroughly checked by the second reviewer. Disagreements were resolved by discussion and, if necessary, by arbitration involving the third reviewer. The risk of bias was assessed for all included studies and reviews. Randomised trials were assessed with the Cochrane risk of bias, non-randomised studies with the Cochrane Risk Of Bias In Non-randomised Studies - of Interventions and systematic reviews with the ROBIS (tool to assess risk of bias in systematic reviews) tool. ${ }^{35-37}$ The level of evidence of studies and reviews that met the inclusion criteria were summarised by outcome (proxy indicators) including a quality assessment in a tabular form. For each proxy indicator, the summary of findings (SOFs) table includes the number of studies, a summary of the intervention effect and a measure of the quality of evidence for each outcome according to GRADE. ${ }^{38-40}$ Existing GRADE assessments of systematic reviews have been included after verification and are marked with an asterisk (*) in the SOF table.

\section{Delphi consensus}

A three-step modified Delphi method was used to add additional proxy indicators and to establish consensus on the interventions' (proxy indicators) potential to reduce morbidity and mortality, if they should be considered an 'essential' intervention, and the appropriate level of care.

Thirteen international experts, with backgrounds in obstetrics and neonatal care, from different regions were approached. All of them agreed to participate and all completed the three rounds.

In round 1, the experts added potential proxy indicators to the provisional list (table 1). Some proxy indicators may have been missed in the systematic review due to for example, very low GRADE quality, as some interventions could not be conducted as randomised studies for ethical reasons.

In round 2, the completed list of indicators was circulated to the experts and they were asked to assess each, as proxy-indicator identified intervention according to (1) their potential to reduce maternal and neonatal morbidity and mortality, (2) whether they should be considered an 'essential' intervention and (3) the appropriate level of care (primary, referral or both). An essential intervention was defined as an essential medical 
Table 1 Summary of findings table

\begin{tabular}{lllcc}
\hline Outcome group & Outcome & Effect & & $\begin{array}{c}\text { Quality of the } \\
\text { Studies }\end{array}$ \\
\hline evidence (GRADE)
\end{tabular}

Folic acid supplementation and fortification ${ }^{42}$

Neonatal outcome $\begin{aligned} & \text { Primary prevention of neural tube } \\ & \text { defect }\end{aligned} \quad$ RR 0.38, 95\% Cl 0.29 to $0.51 \quad 4 \quad$ Moderate*

\section{Pregnancy}

Multiple micronutrient supplementation (with iron and folic acid) ${ }^{43}$

$\begin{array}{llllll}\text { Neonatal outcome } & \text { Low birth weight } & \text { RR } 0.88,95 \% \text { Cl } 0.85 \text { to } 0.90 & 15 & \text { High* } \\ \text { Neonatal outcome } & \text { Stillbirth } & \text { RR } 0.92,95 \% \text { Cl } 0.86 \text { to } 0.99 & 15 & \text { High* }\end{array}$

Administration/advice of folic acid to women with history of baby of neural tube defect (NTD) ${ }^{44}$

$\begin{array}{llll}\text { Neonatal outcome } & \begin{array}{l}\text { Secondary neural tube defect } \\ \text { reduction }\end{array} & \text { RR 0.30, 95\% Cl 0.14 to 0.65 High } & 3\end{array}$

Diet supplementation (high-energy biscuits) for chronically undernourished women ${ }^{50}$

\begin{tabular}{|c|c|c|c|c|}
\hline Neonatal outcome & Stillbirth & OR $0.47,95 \% \mathrm{Cl} 0.23$ to 0.99 & 1 & Low \\
\hline Neonatal outcome & Mortality within 7 days & OR $0.54,95 \% \mathrm{Cl} 0.35$ to 0.85 & 1 & Low \\
\hline \multicolumn{5}{|c|}{ Tetanus toxoid immunisation (at least two vaccinations) ${ }^{51} 110$} \\
\hline Neonatal outcome & $\begin{array}{l}\text { Tetanus-specific neonatal } \\
\text { mortality }\end{array}$ & RR $0.06,95 \% \mathrm{Cl} 0.02$ to 0.20 & 2 & Moderate* $^{*}$ \\
\hline Neonatal outcome & $\begin{array}{l}\text { Preventing neonatal tetanus against } \\
\text { neonatal death }\end{array}$ & RR $0.02,95 \% \mathrm{Cl} 0.00$ to 0.30 & 1 & Moderate* $^{*}$ \\
\hline
\end{tabular}

Syphilis screening with treatment ${ }^{53}$

$\begin{array}{llllll}\text { Neonatal outcome } & \text { Stillbirth } & \text { RR } 0.18,95 \% \mathrm{Cl} 0.10 \text { to } 0.33 & 8 & \text { Low }^{*} \\ \text { Neonatal outcome } & \text { Neonatal mortality } & \text { RR } 0.20,95 \% \mathrm{Cl} 0.13 \text { to } 0.32 & 5 & \text { Low }^{*}\end{array}$

Routine drug administration to prevent malaria and its consequences in pregnant women in areas of moderate to high malaria transmission $^{55}$

\begin{tabular}{|c|c|c|c|c|}
\hline Maternal outcome & $\begin{array}{l}\text { Severe anaemia (during the third } \\
\text { trimester) }\end{array}$ & RR $0.60,95 \% \mathrm{Cl} 0.47$ to 0.75 & 5 & $\mathrm{High}^{*}$ \\
\hline Maternal outcome & Antenatal parasitaemia & RR $0.39,95 \% \mathrm{Cl} 0.26$ to 0.58 & 8 & High* $^{*}$ \\
\hline Maternal outcome & Maternal death & RR $0.79,95 \% \mathrm{Cl} 0.29$ to 2.20 & 2 & Moderate* \\
\hline Neonatal outcome & Neonatal mortality & RR $0.69,95 \% \mathrm{Cl} 0.49$ to 0.98 & 6 & High $^{*}$ \\
\hline Neonatal outcome & Preterm birth & RR $0.82,95 \% \mathrm{Cl} 0.70$ to 0.96 & 14 & Moderate* \\
\hline Neonatal outcome & Low birth weight & $\mathrm{RR} 0.82,95 \% \mathrm{Cl} 0.71$ to 0.94 & 14 & Moderate $^{\star}$ \\
\hline \multicolumn{5}{|c|}{ Prevention and management of HIV and prevention of mother-to-child transmission in pregnancy } \\
\hline \multicolumn{5}{|l|}{ Rapid HIV testing ${ }^{58}$} \\
\hline
\end{tabular}


Table 1 Continued

\section{Pregnancy}

Antiretroviral therapy, for example, Zidovudine given to mothers from 36 weeks' gestation during labour ${ }^{60}$
Neonatal outcome Reduced HIV infection at 4-8 weeks
Efficacy $43.78 \%$,
High

$95 \% \mathrm{Cl} 9.05$ to 60.05

Adherence to antiretroviral medication; mobile phone messages ${ }^{61}$

$\begin{array}{llllll}\text { Maternal outcome } & \text { Viral load suppression at } 52 \text { weeks } & \text { RR 0.83, 95\% Cl } 0.69 \text { to } 0.99 & 1 & \text { High* } \\ \text { Maternal outcome } & \text { ART adherence at 48-52 weeks } & \text { RR 0.82, 95\% Cl 0.72 to 0.94 } & 2 & \text { High* }\end{array}$

Management of prelabour rupture of membranes and preterm labour

Calcium channel blockers for women in preterm labour ${ }^{63}$
Neonatal outcome Reduction in birth less than 48 hours
RR $0.30,95 \% \mathrm{Cl} 0.21$ to 0.43
2
Low $^{*}$ after trial entry

Antenatal corticosteroids for accelerating foetal lung maturation for women at risk of preterm birth ${ }^{64}$
Neonatal outcome Neonatal mortality
RR $0.69,95 \% \mathrm{Cl} 0.58$ to 0.81
18
High*

External cephalic version for breech presentation at term (spinning babies) ${ }^{112}$

Neonatal outcome Perinatal death

RR $0.39,95 \% \mathrm{Cl} 0.09$ to 1.64

8

Low $^{\star}$

Prevention and management of hypertension in pregnancy

Ultrasound for detection of pre-eclampsia ${ }^{6768}$ eclampsia

\begin{tabular}{|c|c|c|c|c|}
\hline Maternal outcome & $\begin{array}{l}\text { Increased pulsatility index with } \\
\text { notching (low risk patients) }\end{array}$ & PLR $7.5,95 \%$ CI 5.40 to 10.20 & 1 & Low \\
\hline Maternal outcome & $\begin{array}{l}\text { Increased pulsatility index with } \\
\text { notching (high risk patients) }\end{array}$ & PLR 21, 95\% Cl 5.50 to 80.50 & 1 & Low \\
\hline
\end{tabular}

Maternal calcium supplementation ${ }^{70} 73$

$\begin{array}{ll}\text { Maternal outcome } & \text { Severe pre-eclampsia } \\ \text { Maternal outcome } & \text { Gestational hypertension } \\ \text { Maternal outcome } & \text { Pre-eclampsia } \\ \text { Neonatal outcome } & \text { Preterm birth }\end{array}$

Antiplatelets for pre-eclampsia (low dose aspirin) ${ }^{74}$

\begin{tabular}{|c|c|c|c|c|}
\hline Maternal outcome & Pre-eclampsia & RR $0.83,95 \% \mathrm{Cl} 0.77$ to 0.89 & 43 & MODERATE* \\
\hline \multicolumn{5}{|l|}{ Magnesium sulfate ${ }^{7879}$} \\
\hline Maternal outcome & Eclampsia & RR $0.41,95 \% \mathrm{Cl} 0.29$ to 0.58 & 6 & High* $^{*}$ \\
\hline Maternal outcome & $\begin{array}{l}\text { Case fatality rate of severe pre- } \\
\text { eclampsia and eclampsia }\end{array}$ & RR $0.11,95 \% \mathrm{Cl} 0.07$ to 0.16 & 1 & Low \\
\hline \multicolumn{5}{|c|}{ Early administration of magnesium sulfate (at home before referral) ${ }^{80}$} \\
\hline Maternal outcome & $\begin{array}{l}\text { Case fatality rate of severe pre- } \\
\text { eclampsia and eclampsia }\end{array}$ & RR $0.21,95 \% \mathrm{Cl} 0.06$ to 0.72 & 1 & Low \\
\hline \multicolumn{5}{|c|}{ Management of unintended pregnancy } \\
\hline \multicolumn{5}{|c|}{ Combination of contraceptive-promoting and educational intervention ${ }^{82}$} \\
\hline Maternal outcome & $\begin{array}{l}\text { Unintended pregnancy among } \\
\text { adolescents }\end{array}$ & RR $0.6695 \% \mathrm{Cl} 0.50$ to 0.87 & 4 & Moderate* \\
\hline \multicolumn{5}{|c|}{ Medications for induced abortion (mifepristone and misoprostol) ${ }^{83}$} \\
\hline Maternal outcome & $\begin{array}{l}\text { No difference in complete abortion } \\
\text { rates between medication and clinics } \\
\text { group }\end{array}$ & OR $0.80,95 \% \mathrm{Cl} 0.50$ to 1.50 & 9 & Moderate \\
\hline
\end{tabular}

\section{Childbirth}

Induction of labour for prolonged pregnancy (uterotonics: oxytocin and misoprostol) ${ }^{113}$
Neonatal outcome Perinatal mortality
RR $0.31,95 \% \mathrm{Cl} 0.11$ to 0.88
19
Moderate

Continued 
Table 1 Continued

\section{Childbirth}

Clean birth and postnatal practices at facility ${ }^{85}$

$\begin{array}{llllll}\text { Neonatal outcome } & \text { Neonatal mortality from sepsis } & \text { RR 0.73, 95\% Cl 0.64 to 0.76 } & \text { Delphi } & \text { Low* } \\ \text { Neonatal outcome } & \text { Neonatal mortality from sepsis } & \text { RR 0.85, 95\% Cl 0.80 to 0.90 } & \text { Delphi } & \text { Low* }\end{array}$

Birth attendant hand washing before birth ${ }^{85}$

Neonatal outcome Cord infection $\quad$ RR $0.70,95 \% \mathrm{Cl} 0.61$ to $0.80 \quad 2 \quad$ Moderate*

Management of postpartum haemorrhage

Active management of third stage of labour (AMTSL) $)^{88}$
Maternal outcome Maternal $\mathrm{Hb}<9 \mathrm{~g} / \mathrm{dL} 24-72$ hours postpartum
RR $0.50,95 \% \mathrm{Cl} 0.3$ to 0.83
$2 \quad$ Low $^{*}$

Controlled cord traction (as part of AMTSL) ${ }^{86}$

Maternal outcome Blood loss $>500 \mathrm{~mL} \quad$ RR 1.07, 95\% Cl 1.00 to $1.14 \quad 2 \quad$ High*

Preventive uterotonic drugs in the absence of active management of labour

Oxytocin (when available) $)^{89}$

$\begin{array}{lllll}\text { Maternal outcome } & \text { Active bleeding controlled within } & \text { RR } 0.94,95 \% \mathrm{Cl} 0.91 \text { to } 0.98 & 1 & \text { High } \\ 20 \mathrm{~min} & \end{array}$

Oral misoprostol in preventing postpartum haemorrhage (PPH) (when injectable uterotonics not available) ${ }^{90}$

$\begin{array}{cllcc}\text { Maternal outcome } & \text { Blood loss }>1000 \mathrm{~mL} & \text { RR 0.66, 95\% Cl } 0.45 \text { to } 0.98 & 1 & \text { High } \\ \text { Uterine balloon tamponade (UBT) (condom catheter) } & & & \\ \text { Maternal outcome } & \text { UBT successfully treated PPH } & 97 \% \text { (234 out of } 241 \text { cases) } & 13 & \text { Low } \\ \text { Maternal outcome } & \text { All-cause survival } & 95 \% \text { (90 out of } 201 \text { cases) } & 1 & \text { Low } \\ \text { Maternal outcome } & \text { Successful treatment of PPH } & 97 \% \text { (223 out of } 229 \text { cases) } & 1 & \text { Moderate }\end{array}$

\section{Neonatal care}

Umbilical cord antiseptics in community and primary care settings ${ }^{85} 99$

$\begin{array}{ccccc}\text { Neonatal outcome } & \text { Neonatal mortality } & \text { RR } 0.81,95 \% \text { Cl } 0.71 \text { to } 0.92 & 3 & \text { High* } \\ \text { Neonatal outcome } & \text { Omphalitis/infections } & \text { RR } 0.77,95 \% \text { Cl } 0.63 \text { to } 0.94 & 3 & \text { High } \\ \text { Early skin to skin contact }{ }^{* 5} & & & \end{array}$

\begin{tabular}{|c|c|c|c|c|}
\hline Neonatal outcome & Breast feeding $0-4$ months postbirth & $\mathrm{RR} 1.27,95 \% \mathrm{Cl} 1.06$ to 1.53 & 13 & Moderate \\
\hline Neonatal outcome & $\begin{array}{l}\text { Hypothermic neonate, rectal } \\
\text { temperature }\end{array}$ & OR $2.90,95 \% \mathrm{Cl} 1.69$ to 5.05 & 1 & Moderate \\
\hline Neonatal outcome & $\begin{array}{l}\text { Hypothermic neonate, tympanic } \\
\text { temperature }\end{array}$ & OR $4.67,95 \% \mathrm{Cl} 2.62$ to 8.38 & 1 & Moderate \\
\hline
\end{tabular}

Early initiation of breast feeding (within the first 24 hours) ${ }^{96}$
Neonatal outcome Neonatal mortality
RR $0.56,95 \%$ Cl 0.40 to $0.79 \quad 3 \quad$ Moderate* $^{*}$

Exclusive breast feeding in the first month of life ${ }^{97}$
Neonatal outcome Neonatal mortality exclusive versus

OR $0.27,95 \% \mathrm{Cl} 0.15$ to $0.49 \quad 2 \quad$ Moderate* $^{*}$
partial breast feeding

Prophylactic vitamin $\mathrm{K}$ for vitamin $\mathrm{K}$ deficiency bleeding in neonates ${ }^{100}$

Neonatal outcome Any moderate to severe bleeding $\quad$ RR 0.19, 95\% Cl 0.08 to $0.46 \quad 1 \quad$ Low $^{*}$

Interventions for small and ill babies

Kangaroo mother care for preterm and for <2000 $\mathrm{g}_{\text {babies }} 33103$

$\begin{array}{llllll}\text { Neonatal outcome } & \text { Neonatal mortality at discharge } & \text { RR 0.60, 95\% Cl } 0.39 \text { to } 0.92 & 8 & \text { High } \\ \text { Neonatal outcome } & \text { Neonatal mortality at latest follow-up } & \text { RR 0.67, 95\% Cl 0.48 to 0.95 } & 11 & \text { High }\end{array}$

Neonatal resuscitation and immediate assessment at facility ${ }^{102}$

Neonatal outcome Early neonatal deaths $\quad$ RR 0.62, 95\% Cl 0.41 to $0.94 \quad 3 \quad$ Moderate*

Continued 


\section{Table 1 Continued}

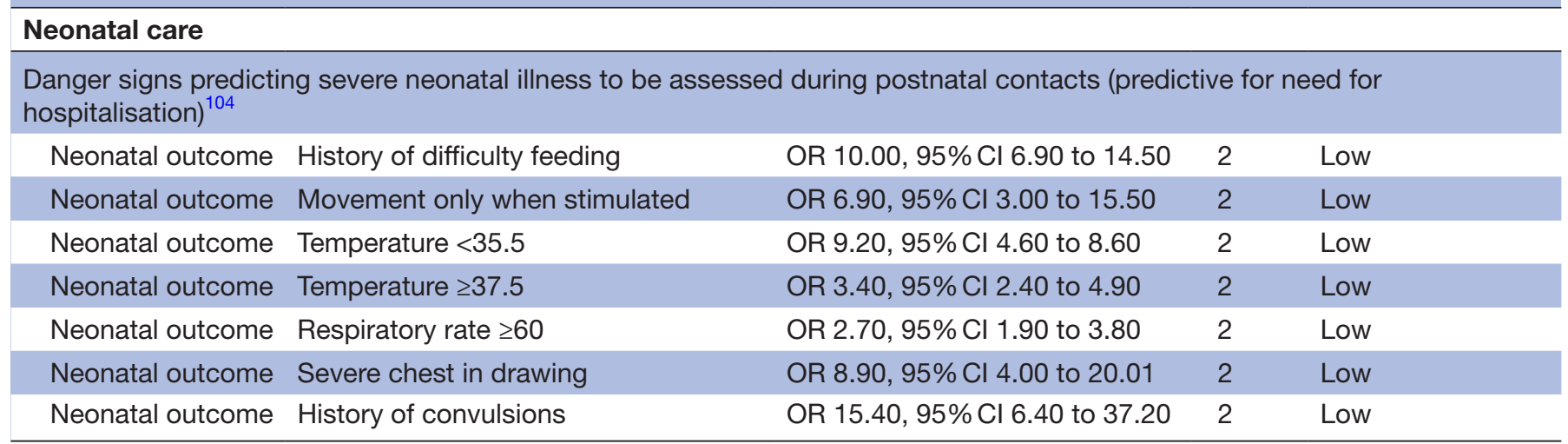

intervention, or 'signal function', that treat the major causes of maternal/neonatal morbidity and mortality and that should be prioritised. Primary level care was defined as care provided by a nurse, family physician or other type of health worker. For example, a rural health centre in Africa would be considered as primary level. Referral level care was defined as care provided in hospitals in general (district or referral); the health care providers at this level are professionals.

The rankings were summarised using the median and the IQR and included in a repeat version of the questionnaire.

In round 3, the experts reranked their agreement with each statement, with the opportunity to change their score in view of the group's response. The rerankings were summarised and assessed for degree of consensus using IQRs for continuous numerical scales and were accepted when the IQR was 2 or less.

The results of the Delphi consensus are summarised in table 2 and are rated as low (+) if the median was between $0-$ and 3 , medium (++) if the median was between 4 and 6 and high $(+++)$ if the median was between 7 and 9 .

\section{Patient involvement}

Patients were not involved in setting the research question, the outcome measures, the design or the implementation of the study. No patients were asked to advise on interpretation or writing up of results. No patients were advised on dissemination of the present study and its main results.

\section{RESULTS OF THE SYSTEMATIC REVIEW}

Our initial search identified 1725 publications, 44 additional records were identified through hand searching. The title and abstract scan resulted in 141 publications that underwent full-text review. Forty-four articles met our selection criteria after the full-text review. The results of the review are 40 potential proxy indicators that are summarised in the SOF table (table 1).

\section{Preconception}

The preconception interventions reviewed included birth spacing and micronutrient supplementation.

Higher risk for preterm birth and low birth weight (LBW) are associated to short interpregnancy intervals (IPIs) (less than 6 months) as well as long IPIs (60 months or more after birth), compared with an IPI of 18-23 months. ${ }^{41}$

Folic acid supplementation and fortification are effective in reducing neonatal mortality. ${ }^{42}$

\section{Pregnancy}

The antenatal interventions reviewed included micronutrient and diet supplementation, maternal immunisation, screening and management of infections (syphilis, HIV/ AIDS and malaria), prevention and management of pregnancy-induced disorders (notably arterial hypertension), management of prelabour rupture of membranes and preterm labour, drug misuse and management of unintended pregnancy.

Multiple micronutrient supplementation (iron and folic acid) is improving birth outcomes. ${ }^{43}$ For women with a history of a baby with neural tube defect, folic acid reduces the recurrence by $70 \%{ }^{44}$

LBW is a major contributor to neonatal mortality and over $95 \%$ of LBW babies are born in LMIC countries. ${ }^{45}$ While there has been controversy about whether dietary supplementation (eg, high energy biscuits for chronically undernourished women) in pregnancy can increase birth weight, ${ }^{46-49}$ the 5 -year prospective randomised controlled trial in 28 rural Gambian villages by Ceesay $e t$ $a \check{l}^{0}$ concludes that supplementation significantly reduces perinatal mortality in at-risk mothers.

Major progress has been achieved for neonatal tetanus, but it remains a significant preventable cause of neonatal mortality globally. ${ }^{2}$ Immunisation of pregnant women or women of reproductive age with at least two doses of tetanus toxoid is estimated to reduce mortality from neonatal tetanus by $94 \% .^{51}$

Infection is a well-acknowledged cause of stillbirth and accounts for an estimated half of all stillbirth, particularly in LMICs. ${ }^{52}$ Syphilis screening and treatment with 
Table 2 Delphi consensus summary table

Mortality/

morbidity Essential Primary Referral

\section{Preconception}

Family planning

Birth spacing: interpregnancy interval between 6 months and under 60 months

\begin{tabular}{|c|c|c|c|c|}
\hline $\begin{array}{l}\text { Combination of contraceptive-promoting and educational interventions } \\
\text { to avoid unwanted pregnancy* }\end{array}$ & +++ & +++ & $\checkmark$ & - \\
\hline Folic acid supplementation and fortification & ++ & +++ & $\checkmark$ & $\checkmark$ \\
\hline $\begin{array}{l}\text { Administration/advice folic acid to women with history of baby of neural } \\
\text { tube defects* }\end{array}$ & +++ & +++ & $\checkmark$ & $\checkmark$ \\
\hline Advise for cessation of alcohol consumption* & +++ & +++ & $\checkmark$ & $\checkmark$ \\
\hline $\begin{array}{l}\text { Education (maternal age, physiology, nutritional status of mother: body } \\
\text { mass index (BMI) and so on) }{ }^{\star}\end{array}$ & +++ & +++ & $\checkmark$ & - \\
\hline Weight reduction in overweight, obese and morbidly obese women* & +++ & +++ & $\checkmark$ & $\checkmark$ \\
\hline Rubella screening* & ++ & ++ & $\checkmark$ & - \\
\hline Haemoglobin level/anaemiastatus before pregnancy ${ }^{\star}$ & +++ & +++ & $\checkmark$ & $\checkmark$ \\
\hline
\end{tabular}

\section{Pregnancy}

Iron and folic acid supplementation (multiple micronutrient) Iron supplementation from second trimester to 3 months postnatal ${ }^{*}$

$\begin{array}{cccc}+++ & +++ & \checkmark & \checkmark \\ +++ & +++ & \checkmark & \checkmark \\ +++ & +++ & \checkmark & - \\ ++ & ++ & \checkmark & \checkmark\end{array}$

Nutritional status of mother: $\mathrm{BMI}^{*}$

Diet supplementation (high energy biscuits) for chronically undernourished ++ women

\begin{tabular}{|c|c|c|c|c|}
\hline Tetanus toxoid immunisation (at least two vaccinations) & +++ & +++ & $\checkmark$ & $\checkmark$ \\
\hline Whooping cough immunisation at $\mathrm{T} 2$ or $\mathrm{T}^{*}$ & +++ & +++ & $\checkmark$ & $\checkmark$ \\
\hline Syphilis screening with treatment & ++ & +++ & $\checkmark$ & $\checkmark$ \\
\hline Intermittent preventive treatment of malaria in pregnancy & +++ & +++ & $\checkmark$ & $\checkmark$ \\
\hline $\begin{array}{l}\text { Identification of bacteriuria and treatment (urine culture and antibiotic } \\
\text { treatment of bacteriuria) }\end{array}$ & +++ & +++ & $\checkmark$ & $\checkmark$ \\
\hline $\begin{array}{l}\text { Palpation of uterus and measurement of fundus height (for detecting } \\
\text { problems with foetal growth) }\end{array}$ & ++ & ++ & $\checkmark$ & - \\
\hline Advise for cessation of alcohol consumption (adverse effect of alcohol)* & +++ & +++ & $\checkmark$ & $\checkmark$ \\
\hline Smoking cessation during pregnancy (psychosocial interventions) & +++ & +++ & $\checkmark$ & $\checkmark$ \\
\hline $\begin{array}{l}\text { Management of unintended pregnancy: medications for induced abortion } \\
\text { (mifepristone and misoprostol) }\end{array}$ & +++ & +++ & $\checkmark$ & $\checkmark$ \\
\hline $\begin{array}{l}\text { Thyroxine for euthyroid women with positive antithyroid antibodies and } \\
\text { recurrent miscarriages* }\end{array}$ & ++ & ++ & - & $\checkmark$ \\
\hline Kegel exercises to reduce stress incontinence* & + & + & $\checkmark$ & $\checkmark$ \\
\hline $\begin{array}{l}\text { Fasting blood sugar checking for high-risk population for gestational } \\
\text { diabetes mellitus }^{\star}\end{array}$ & +++ & +++ & $\checkmark$ & $\checkmark$ \\
\hline \multicolumn{5}{|l|}{ Availability of ultrasound } \\
\hline $\begin{array}{l}\text { Foetal echography screening: abnormalities, malformations, growth } \\
\text { retardation, macrosomia* }\end{array}$ & ++ & ++ & - & $\checkmark$ \\
\hline \multicolumn{5}{|l|}{$\begin{array}{l}\text { Prevention and management of HIV and prevention of mother-to-child } \\
\text { transmission in pregnancy }\end{array}$} \\
\hline Rapid HIV testing & +++ & +++ & $\checkmark$ & $\checkmark$ \\
\hline Antiretroviral therapy & +++ & +++ & $\checkmark$ & $\checkmark$ \\
\hline Adherence to antiretroviral medication; mobile phone messages & +++ & +++ & $\checkmark$ & $\checkmark$ \\
\hline
\end{tabular}


Table 2 Continued

\section{Pregnancy}

Management of prelabour rupture of membranes and preterm labour

Calcium channel blockers for women in preterm labour

Antenatal corticosteroids for accelerating foetal lung maturation for women at risk of preterm birth

Antenatal transfer to higher level of neonatal care*

Magnesium sulfate in preterm delivery before 34 weeks for neuroprotection*

Antibiotics in management of preterm prelabour rupture of membranes

$\begin{array}{cccc}++ & +++ & \checkmark & \checkmark \\ +++ & +++ & \checkmark & \checkmark\end{array}$

Prevention and management of hypertension in pregnancy

Early detection of pre-eclampsia by signs and symptoms*

(Better) implementation/adherence to protocols for pregnancy-induced hypertension $(\mathrm{PIH})^{\star}$

Antihypertensive drugs to treat $\mathrm{PIH}^{\star}$

$+++\quad+++$

$+++++$

$\checkmark \quad \checkmark$

Maternal calcium supplementation (in areas with poor calcium diet)

Antiplatelet drugs for pre-eclampsia (low-dose aspirin)

$+++$

$+++$

Use of magnesium sulfate

Early administration of magnesium sulfate (before referral)

$\begin{array}{cccc}+++ & +++ & \checkmark & \checkmark \\ +++ & +++ & \checkmark & \checkmark \\ +++ & +++ & \checkmark & \checkmark \\ +++ & +++ & \checkmark & \checkmark \\ +++ & +++ & \checkmark & \checkmark \\ +++ & +++ & \checkmark & \checkmark \\ +++ & +++ & \checkmark & \checkmark\end{array}$

\section{Childbirth}

External cephalic version for breech presentation at term

Clean birth and postnatal practices at facility

Birth attendant hand washing before birth

Foetal heart (intermittent) auscultation*

Early referral if prolonged labour*

Instrumental vaginal delivery (eg, Kiwi vacuum extractor)*

Delivery of baby to mother's abdomen*

Antibiotic prophylaxis against streptococcus $B^{\star}$

$+++\quad+++$

$++$

$+++\quad+++$

$+++\quad++$

$+++$

$+++$

$+++$

$+++$

$+++$

$+++$

$+++$

$+++++$

$+++$

$+++$

Induction of prolonged pregnancy

Induction of labour for prolonged pregnancy with uterotonics (oxytocin and misoprostol)

Induction with Foley catheter*

$+++$

$+++$

Management of postpartum haemorrhage

Active management of third stage of labour

Use of uterotonics for preventing postpartum haemorrhage (PPH)

$+++$

$+++$

$+++$

$+++$

prevention: oxytocin preferred (if available), oral misoprostol second

choice (when injectable uterotonics not available)

Uterine balloon tamponade (condom catheter)

Measurement of blood loss (blood collection bag and blood collection sheets) ${ }^{*}$

Recombinant factor VII in massive $\mathrm{PPH}^{*}$

Tranexamic acid in postpartum haemorrhage (PPH) ${ }^{\star}$

Uterine massage and emptying the bladder*

\section{Neonatal care}

Umbilical cord antiseptics in community and primary care settings

Early skin-to-skin contact

\begin{tabular}{cccc}
+++ & +++ & $\checkmark$ & $\checkmark$ \\
+++ & +++ & $\checkmark$ & $\checkmark$ \\
++ & ++ & $\checkmark$ & $\checkmark$ \\
+++ & +++ & $\checkmark$ & $\checkmark$ \\
+++ & +++ & $\checkmark$ & $\checkmark$ \\
\hline
\end{tabular}

$+++$

$+++$

$+++$

$+++$

$\checkmark$

\section{$\checkmark$}

$\checkmark$ 
Table 2 Continued

\begin{tabular}{|c|c|c|c|c|}
\hline \multicolumn{5}{|l|}{ Neonatal care } \\
\hline $\begin{array}{l}\text { Avoidance of hypothermia (delaying bathing until the second day of life, } \\
\text { temperature monitoring) }\end{array}$ & +++ & +++ & $\checkmark$ & $\checkmark$ \\
\hline Exclusive breast feeding in the first months of life & +++ & +++ & $\checkmark$ & $\checkmark$ \\
\hline Prophylactic vitamin $\mathrm{K}$ for vitamin $\mathrm{K}$ deficiency bleeding in neonates & +++ & +++ & $\checkmark$ & $\checkmark$ \\
\hline $\begin{array}{l}\text { BCG vaccination before discharge (in areas where tuberculosis is } \\
\text { common)* }\end{array}$ & +++ & +++ & $\checkmark$ & $\checkmark$ \\
\hline Congenital cardiac disease screening ${ }^{*}$ & ++ & ++ & - & $\checkmark$ \\
\hline $\begin{array}{l}\text { Advise and teach mother to wash hands after change of nappy (infection } \\
\text { prevention)* }\end{array}$ & +++ & +++ & $\checkmark$ & $\checkmark$ \\
\hline $\begin{array}{l}\text { Nasal continuous positive airway pressure for neonates with respiratory } \\
\text { distress syndrome* }\end{array}$ & +++ & +++ & - & $\checkmark$ \\
\hline Antibiotics for sepsis* & +++ & +++ & $\checkmark$ & $\checkmark$ \\
\hline $\begin{array}{l}\text { Prevention of hypoglycaemia for small for gestational age and preterm } \\
\text { babies (monitor glycaemia and early feeding/glucose) }\end{array}$ & +++ & +++ & $\checkmark$ & $\checkmark$ \\
\hline Neonatal resuscitation and immediate assessment at facility & +++ & +++ & $\checkmark$ & $\checkmark$ \\
\hline $\begin{array}{l}\text { Danger signs predicting severe neonatal illness to be assessed during } \\
\text { postnatal contacts (predictive for need for hospitalisation) }\end{array}$ & +++ & +++ & $\checkmark$ & $\checkmark$ \\
\hline \multicolumn{5}{|l|}{ Postpartum* } \\
\hline
\end{tabular}

penicillin reduces syphilis-related stillbirth by $82 \%$ and syphilis-specific neonatal death by $80 \% .^{53}$ The effect in all studies was large, and there is a clear biological mechanism, but as only few of the included studies were adjusted for potential confounding factors, quality of the evidence was graded as low. ${ }^{5354}$

Intermittent preventive treatment of malaria in pregnancy is a routine drug administration to prevent malaria and its consequences in pregnant women in areas of moderate to high malaria transmission. Routine chemoprevention for malaria and its consequences have been extensively tested in RCTs, with clinically important benefits on anaemia and parasitaemia in the mother ${ }^{55}$ and reduced neonatal mortality. ${ }^{51}$

The majority of HIV-infected children acquired their infections as a result of mother-to-child transmission during pregnancy, labour or breast feeding. In areas with lower health services infrastructure, infections may stay undetected, which is problematic as early diagnosis and treatment demonstrated improved clinical outcomes. ${ }^{5657}$ About $50 \%$ of people living with HIV are unaware of their diagnosis. ${ }^{58}{ }^{59}$ Reliable point-of-care HIV diagnostic tests, administering antiretroviral drugs to the HIV-infected mother and/or to her child during pregnancy, labour or breast feeding and adherence to antiretroviral medication are essential to prevent vertical transmission. ${ }^{60-62}$

Preterm birth is a major contributor to perinatal mortality and morbidity. Calcium channel blockers for women in preterm labour have benefits over placebo or no treatment in terms of postponement of birth and were shown to have benefits over beta-mimetics with respect to prolongation of pregnancy, serious neonatal morbidity and maternal adverse effects. ${ }^{63}$ Corticosteroid therapy used to accelerate foetal lung maturation for women at risk of preterm birth is relatively inexpensive and feasible to implement at primary level in an LMIC context if skilled health care providers are available to identify women at risk of preterm birth and administer intramuscular injections. ${ }^{6465}$

Gestational hypertensive diseases, including pregnancy-induced hypertension, pre-eclampsia and eclampsia are leading causes of maternal and infant morbidity and mortality. ${ }^{66}$ Early detection is crucial for monitoring and prevention. Pre-eclampsia is related to a lack of placental invasion, and its complications on the pregnancy can be detected by ultrasound. ${ }^{67-69}$ Gestational calcium supplementation is associated with a reduction in hypertensive disorders in pregnancy, especially for women with a low 
calcium intake $\mathrm{e}^{70-72}$ and reduces gestational hypertension, severe pre-eclampsia and pre-eclampsia. ${ }^{70}$ Administration of antiplatelets (eg, low-dose aspirin) to pregnant women at high risk of pre-eclampsia or those with gestational hypertension prevents pre-eclampsia. ${ }^{44} 74$ Magnesium sulfate is one of the most effective anticonvulsant to protect women from severe pre-eclampsia and eclampsia and, if administered timely, reduces the risk of seizure repetition and reduces case fatality rate of severe pre-eclampsia and eclampsia. ${ }^{75-77}$ Magnesium sulfate more than halves the risk of eclampsia. ${ }^{78} 79$ For women who received a magnesium sulfate injection before referral, case fatality rate of severe pre-eclampsia and eclampsia was reduced by $79 \% .{ }^{80}$ Even though the effect was strong, due to a small sample size, the evidence was graded low. WHO recommends that magnesium sulfate is administered to women with severe pre-eclampsia before they are transferred to a secondary or tertiary level facility. ${ }^{81}$

A combination of contraceptive promoting and educational interventions reduce unintended pregnancy, while only contraceptive-promoting interventions showed little or no difference in the risk of unintended first pregnancy (RR $1.01,95 \%$ CI $(0.81$ to 1.26$)){ }^{82}$

Medical abortion uses drugs (mifepristone and misoprostol) to terminate a pregnancy and is an important alternative to surgical methods of pregnancy termination, especially in areas where access to surgical termination is not available. ${ }^{83} 84$

\section{Childbirth}

Interventions during and close to childbirth include clean birth and postnatal practices, the management of postpartum haemorrhage and preventive uterotonic drugs in the absence of active management of labour.

Clean birth practices include: hand washing, clean perineum, clean birth surface, cutting of the umbilical cord using a clean implement and clean cord tying. ${ }^{85}$ Clean postnatal practices include: chlorhexidine, other antimicrobial applications to the cord, avoidance of harmful cord applications, skin applications and emollients and hand washing. ${ }^{85}$ These are estimated to reduce neonatal mortality in a facility and home setting. Even though the evidence quality is low or very low, as there is strong biological plausibility, the GRADE recommendation for these practices is strong. ${ }^{5185}$

Active management of third stage of labour (AMTSL) is a package of three components or steps: (1) administration of an uterotonic, preferably oxytocin, immediately after birth of the baby; (2) controlled cord traction to deliver the placenta, if skilled birth attendants are available $^{8687}$; and (3) massage of the uterine fundus after the placenta is delivered, with administration of an uterotonic as most important part. ${ }^{87}$ In the absence of AMTSL, a preventive uterotonic drug (oxytocin or misoprostol) should be administered by a health worker trained in its use for prevention of preventing postpartum haemorrhage (PPH) ${ }^{87} 89$ If both oxytocin and misoprostol are available, oxytocin is the preferred first-line treatment. ${ }^{8789}$
Oral or sublingual misoprostol compared with placebo is effective in reducing severe and is a suitable first-line treatment alternative for PPH in settings where the use of oxytocin is not feasible. ${ }^{89} 90$

Uterine balloon tamponade is a relatively simple approach and demonstrated to be an effective technique to treat PPH in developed countries but is underused in LMICs due to the high cost of the balloon. A sterile rubber catheter fitted with a condom was developed as innovative low cost alternative in Bangladesh in 2001. ${ }^{91}$ Three studies suggest that condom catheter uterine balloon tamponade (C-UBT) is simple to use, inexpensive, safe and may be used by any healthcare provider involved in delivery for controlling massive PPH. ${ }^{92-94}$

\section{Neonatal care}

Interventions for all neonates include hygienic care, prevention of hypothermia, support for immediate breast feeding and prophylactic vitamin $\mathrm{K}$.

Early skin-to-skin contact benefits breastfeeding outcomes at $0-4$ months postbirth, ${ }^{95}$ while early initiation of breast feeding lowers all-cause neonatal mortality among live birth. ${ }^{96}$ Exclusive breast feeding reduces the risk of neonatal mortality compared with partial breast feeding. ${ }^{97}$

Thermal care (immediate drying, warming, skin to skin and delayed bathing) of neonates prevents hypothermia. ${ }^{44}$ Bathing in warm water 1 hour after delivery is associated with a significant increase in hypothermia in both measurement methods, rectal and tympanic. ${ }^{98}$

Neonatal chlorhexidine cord care reduces the incidence of omphalitis and neonatal mortality. ${ }^{99}$

A single dose of $1 \mathrm{mg}$ of intramuscular vitamin $\mathrm{K}$ after birth is effective in the prevention of classic haemorrhagic disease of the neonate. ${ }^{100}$

Interventions for small and ill neonates include neonatal resuscitation and immediate assessment, prevention of hypothermia and danger signs predicting severe neonatal illness to be assessed during postnatal contacts.

Every year, an estimated 10 million babies require assistance to initiate breathing. Basic neonatal care (warming, drying, stimulation and resuscitation including bag-andmask ventilation) would be sufficient to save most babies in need of resuscitation in low-resource settings. ${ }^{101}$ Training of neonatal resuscitation in facilities could reduce $30 \%$ of intrapartum-related mortality RR $0.70,95 \%$ CI $(0.59$ to $0.84)$ and $38 \%$ of early neonatal mortality. ${ }^{102}$ The coverage of this intervention remains low in countries where most neonatal deaths occur, which presents a missed opportunity to save lives. ${ }^{102}$

Kangaroo mother care (KMC), among other benefits, reduces neonatal mortality. ${ }^{103} \mathrm{KMC}$ in LBW infants is an alternative to conventional neonatal care.

The Young Infants Clinical Signs Study Group developed a single simple algorithm that can identify severe illness in infants aged 0-2 months who are brought to health facilities. ${ }^{104}$ The algorithm was developed from a large prospectively collected dataset and consists of 
seven signs: (1) history of difficulty feeding, (2) history of convulsions, (3) movement only when stimulated, (4) respiratory rate of 60 breaths per minute or more, (5) severe chest in-drawing, (6) temperature of $37.5^{\circ} \mathrm{C}$ or more and (7) temperature below $35.5^{\circ} \mathrm{C}$. Each of these signs is predictive for the need of hospitalisation in infants of the age group 0-6 days and 7-59 days and should be used to identify sick infants that need referral faster. ${ }^{104}$

\section{RESULTS OF THE DELPHI CONSENSUS}

The Delphi experts completed and prioritised the results of the systematic review, resulting in a table of 77 proxy indicators (table 2). Indicators that were added or modified in the Delphi process are marked with an asterisk (*).

\section{DISCUSSION}

Evidence documents the benefits of eHealth tools in terms of increasing satisfaction of health care professionals (HCPs), deisolation, acquisition of new knowledge and their potential impact (largely based on observational studies). ${ }^{3-13}$ However, there is little evidence demonstrating that these tools lead to changes in health behaviours, which have a meaningful impact on the patient outcomes. An evaluation of a mobile tool for health workers in India used an approach that is similar to the proposed proxy indicators, measuring the impact of the mobile tools on key health behaviours. ${ }^{105}$ On the one hand, this evaluation demonstrated the feasibility of the proposed approach, showing large and statistically significant impacts on many outcomes in the antenatal care domain; on the other hand, it accentuated the need to evaluate the impact of eHealth tools on patient outcomes beyond knowledge acquisition. ${ }^{105}$ The evaluation showed that even though there were significant impacts on mother's knowledge on exclusive breast feeding, this did not translate into significant impacts on reported exclusive breast feeding for 6 months. ${ }^{105}$

The main difficulty of evaluating the impact on patient outcomes can be attributed to the limited identification of measurable and reliable indicators. This systematic review identified a set of proxy indicators (table 1) to evaluate the impact of maternal and neonatal eHealth tools in low-resource settings on health outcomes. Experts completed the results with additional proxy indicators, for example, 'Whooping cough immunization at T2 or T3', and reorganised them in a Delphi consensus (table 2). Table 3 provides a summarised view on the identified intervention domains of the proxy indicators, while the granularity of the list of proxy indicators (table 2) is necessary to identify the most appropriate proxy indicators for specific eHealth projects or programmes.

Some of the via the Delphi consensus identified supplementary proxy indicators were not determined in the systematic review, as there were no direct relation to outcomes. They were however added by the experts as they provide essential information for a better case management that may lead to improved outcomes, for example, measurement of blood loss (blood collection bag and blood collection sheets) ${ }^{106}$ or nutritional status of mother (BMI) ${ }^{107}$ For example, systematically collecting information on blood loss does not prevent PPH, but early detection of excess bleeding may allow for fast and efficient treatment. ${ }^{106}$

The experts also added more general proxy indicators like 'Antihypertensive drugs to treat pregnancy-induced hypertension (PIH)' in addition to the more specific ones, for example, antiplatelet drugs for pre-eclampsia (low dose aspirin), which were identified in the systematic review. Furthermore, some additional proxy indicators measure whether cases are managed better, which is assumed to improve outcomes, for example, early referral if prolonged labour or antenatal transfer to higher level of neonatal care. ${ }^{108}$ In practice, they will need to be mapped to the local context, as the appropriate time for referral in case of, for example, prolonged labour varies depending on the location and context (availability of medication and of the facility.

Moreover the experts identified 'Tranexamic acid in post-partum haemorrhage' in the Delphi consensus as an additional proxy indicator. The systematic review did not identify this due to inconclusive literature or poor quality evidence at the time of the systematic review. However, recently, a new randomised, double-blind, placebo-controlled trial was published, concluding that tranexamic acid reduces PPH death of clinically diagnosed women and that early treatment seems to optimise benefits. ${ }^{109}$

\section{Limitations}

The proxy indicators are probably more suitable to evaluate maternal and neonatal eHealth programmes or components of a programme. For specific maternal/ neonatal eHealth programmes or projects (eg, targeted at HIV infected mothers), additional indicators might be identifiable (eg, vertical transmission of HIV/AIDS). Some proxy indicators may also have been overlooked as unforeseen, and disruptive uses of eHealth may emerge and offer unexpected ways to improve practices.

\section{Application}

When applied in future studies, proxy indicators related to the eHealth intervention are identified from table 2. Some of them need to be mapped to the local context, practices and available resources. For example 'the use of uterotonics for PPH prevention': oxytocin is the preferred choice when available, while oral misoprostol should be the second choice, when injectable uterotonics are not available for treatment. ${ }^{89}$ The proxy indicators can detect and attest changes in behaviour and may explain changes in mortality, even if causality cannot be formally demonstrated.

The local mapping enables the utilisation of the proxy indicators in various contexts, while the 'high level' of the indicators allows systemically collecting data from different projects and programmes (collective data/ 
Table 3 Categories of proxy indicators

Category Description

Education

Screening for infectious diseases and risk factors

Education and training of HCPS for interventions that are targeting behaviour changes, knowledge acquisition or awareness of patients or HCPs. Examples of proxy indicators for education are: birth spacing, advice for cessation of alcohol, birth attendant hand washing before birth or avoidance of hypothermia (delaying bathing until the second day of life, temperature monitoring).

Interventions for a better availability and implementation of screening for infectious diseases and risk factors. Examples of proxy indicators are: nutritional status of mother: body mass index, syphilis screening with treatment, fasting blood sugar checking for high-risk population for gestational diabetes mellitus.

$\begin{array}{ll}\text { Availability of ultrasound } & \begin{array}{l}\text { The availability of ultrasound allows the detection of abnormalities, malformations } \\ \text { growth retardation and macrosomia but is also assumed to improve the number } \\ \text { prenatal care visits of the pregnant women. }{ }^{114}\end{array} \\ \text { Management of unintended pregnancy } & \begin{array}{l}\text { The better availability and implementation of the management of unintended } \\ \text { pregnancy. Examples of a proxy indicator is medications for induced abortion } \\ \text { (mifepristone and misoprostol). }\end{array}\end{array}$

Timely referral Timely identification and referral of pregnancy-related complications and emergencies are key factors to reduce maternal and new-born mortality. ${ }^{108}$ Examples of proxy indicators are: antenatal transfer to higher level of neonatal care, early identification of danger signs predicting severe new-born illness to be assessed during postnatal contacts (predictive for need for hospitalisation).

Prevention and management of HIV Interventions for a better availability and implementation of interventions to prevent and manage HIV. Examples of proxy indicators are: rapid HIV testing, adherence to antiretroviral medication and mobile phone messages.

Management of prelabour rupture of Interventions for a better availability and implementation of interventions to manage membranes and preterm labour prelabour rupture of membranes and preterm labour. Examples of proxy indicators are calcium channel blockers for women in preterm labour, antenatal corticosteroids for accelerating foetal lung maturation for women at risk of preterm birth or antibiotics in management of preterm prelabour rupture of membranes.

Prevention and management of hypertension in pregnancy Interventions for a better availability and implementation of interventions to prevent and manage hypertension in pregnancy. Examples of proxy indicators are: (better) implementation/adherence to protocols for pregnancy-induced hypertension, antiplatelet drugs for pre-eclampsia (low dose aspirin) and the use of magnesium sulfate.

\begin{tabular}{ll} 
Induction of prolonged pregnancy & $\begin{array}{l}\text { Interventions for an induction of prolonged pregnancy. Examples of proxy indicators } \\
\text { are: induction of labour for prolonged pregnancy with uterotonics (oxytocin and } \\
\text { misoprostol) or induction with Foley catheter. }\end{array}$ \\
$\begin{array}{ll}\text { Management of postpartum } \\
\text { haemorrhage }\end{array}$ & $\begin{array}{l}\text { Interventions for a better prevention and management of postpartum haemorrhage. } \\
\text { Examples of proxy indicators are: use of uterotonics for PPH prevention: oxytocin } \\
\text { preferred (if available), oral misoprostol second choice (when injectable uterotonics not } \\
\text { available), the measurement of blood loss (blood collection bag and blood collection } \\
\text { sheets) or tranexamic acid in postpartum haemorrhage. }\end{array}$ \\
\hline $\begin{array}{l}\text { Interventions for a better availability and implementation of interventions for small and } \\
\text { Ill babies. Examples of proxy indicators are: parents kangaroo care for preterm and for } \\
<2000 \mathrm{~g} \text { babies or neonatal resuscitation and immediate assessment at facility. }\end{array}$ \\
\hline
\end{tabular}

evidence). Because of the mapping, it is the same proxy indicator for different context, measuring what is locally and temporally relevant and therefore sustainable.

Table 2 could also serve as a checklist when implementing a project or as a basis for the baseline questionnaire and for creating the didactic contents.

\section{CONCLUSION}

The identified proxy indicators provide a workable approach to measuring the impact of eHealth interventions on maternal and neonatal health. However, their validation and calibration in various settings with different methodologies is still required.

The availability of indicators (direct and proxy) facilitates consistent outcome measurements and comparability of studies, ${ }^{29}$ and this methodology could be applied to other domains, for example, chronic diseases.

This implementation research aims at creating evidence to support decision makers to answer questions like "why should we invest in eHealth rather than medical staff, 
immunization or medications?' and to identify and implement solutions with the greatest potential impact on health. The availability of indicators and the possibility to measure and demonstrate scientific evidence for medical benefits that is based on reliable indicators will accelerate decision makers' ability to institutionalise eHealth activities and to commit strategically at the regional and national level.

Acknowledgements The authors would like to thank the following persons (in alphabetical order) for their valuables inputs and useful comments: M. Benissa, N. Bhatta, M. Boulvain, D. Desseauve, 0. Irion, J. Krishnakumar, S. Masheer, N. Najmi, S. Nausheen, R. Pfister, L. Sheikh, S. Sizonenko, B. Stoll, M. Temmerman and G. Walraven

Contributors $\mathrm{CP}$ designed the work with input from AG. CP designed the protocol with input of $A G$ and $L H$. CP did the initial screening of studies. $C P$ and $L H$ rated the studies; AG solved discrepancies in the ratings. $\mathrm{CP}$ extracted the data, which was thoroughly checked and verified by LH. CP drafted the article. AG and LH made a critical revision of the article. All authors gave their final approval of the version to be published.

Funding Department of Radiology and Medical Informatics, Faculty of Medicine, University of Geneva.

Competing interests None declared.

Patient consent Not required.

Provenance and peer review Not commissioned; externally peer reviewed. Data sharing statement № additional data sharing available.

Open access This is an open access article distributed in accordance with the Creative Commons Attribution Non Commercial (CC BY-NC 4.0) license, which permits others to distribute, remix, adapt, build upon this work non-commercially, and license their derivative works on different terms, provided the original work is properly cited, appropriate credit is given, any changes made indicated, and the use is non-commercial. See: http://creativecommons.org/licenses/by-nc/4.0/.

\section{REFERENCES}

1. Victora CG, Requejo JH, Barros AJD, et al. Countdown to 2015: a decade of tracking progress for maternal, newborn, and child survival. The Lancet 2016;387:2049-59.

2. Liu L, Oza S, Hogan D, et al. Global, regional, and national causes of child mortality in 2000-13, with projections to inform post-2015 priorities: an updated systematic analysis. The Lancet 2015;385:430-40.

3. Curran VR, Fleet L, Kirby F. Factors influencing rural health care professionals' access to continuing professional education. Aust $J$ Rural Health 2006;14:51-5.

4. Childs S, Blenkinsopp E, Hall A, et al. Effective e-learning for health professionals and students-barriers and their solutions. A systematic review of the literature-findings from the HeXL project. Health Info Libr J 2005;22(s2):20-32.

5. Clarke A, Lewis D, Cole I, et al. A strategic approach to developing e-learning capability for healthcare. Health Info Libr J 2005;22(s2):33-41.

6. Bagayoko CO, Perrin C, Gagnon M-P, et al. Continuing distance education: a capacity-building tool for the de-isolation of care professionals and researchers. J Gen Intern Med 2013;28:666-70.

7. Bagayoko CO, Niang M, Traoré ST, et al. Deploying portable ultrasonography with remote assistance for isolated physicians in Africa: lessons from a pilot study in Mali. Stud Health Technol Inform 2010;160(Pt 1):554-8.

8. Bediang G, Franck C, Raetzo M-A, et al. Developing clinical skills using a virtual patient simulator in a resource-limited setting. Stud Health Technol Inform 2012;192:102-6.

9. Geissbuhler A, Bagayoko CO, Ly O. The RAFT network: 5 years of distance continuing medical education and tele-consultations over the Internet in French-speaking Africa. Int J Med Inform 2007;76(56):351-6.

10. Bagayoko CO, Gagnon MP, Traoré D, et al. E-Health, another mechanism to recruit and retain healthcare professionals in remote areas: lessons learned from EQUI-ResHuS project in Mali. BMC Med Inform Decis Mak 2014;14:4.
11. Bagayoko C, Traoré D, Thevoz L, et al. Medical and economic benefits of telehealth in low- and middle-income countries: results of a study in four district hospitals in Mali. BMC Health Serv Res 2014;14(Suppl 1):S9.

12. Bediang G, Perrin C, RRd C, et al. The RAFT Telemedicine network in low and middle income countries: educational and clinical services, lessons learnt and perspectives. Front Public Health 2014;2:180.

13. Bagayoko CO, Anne A, Fieschi M, et al. Can ICTs contribute to the efficiency and provide equitable access to the health care system in Sub-Saharan Africa? The Mali experience. Yearb Med Inform 2011;6:33-8.

14. eHealth. Fifty-eighth World Health Assembly, Geneva. Geneva: World Health Organization, 2005.

15. Roine R, Ohinmaa A, Hailey D. Assessing telemedicine: a systematic review of the literature. CMAJ 2001;165:765-71.

16. Ekeland AG, Bowes A, Flottorp S. Effectiveness of telemedicine: A systematic review of reviews. Int J Med Inform 2010;79:736-71.

17. Black AD, Car J, Pagliari C, et al. The impact of eHealth on the quality and safety of health care: a systematic overview. PLoS Med 2011;8:e1000387.

18. Al-Shorbaji $\mathrm{N}$. Is there and do we need evidence on eHealth interventions? IRBM 2013;34:24-7.

19. Al-Shorbaji N, Geissbuhler A. Establishing an evidence base for e-health: the proof is in the pudding. Bull World Health Organ 2012;90:322-22A.

20. Tomlinson M, Rotheram-Borus MJ, Swartz L, et al. Scaling up mHealth: where is the evidence? PLoS Med 2013;10:e1001382.

21. Wootton R. Telemedicine support for the developing world. $J$ Telemed Telecare 2008;14:109-14.

22. Kiberu VM, Mars M, Scott RE. Barriers and opportunities to implementation of sustainable e-Health programmes in Uganda: A literature review. Afr J Prim Health Care Fam Med 2017;9:1-10.

23. Beratarrechea A, Lee AG, Willner JM, et al. The impact of mobile health interventions on chronic disease outcomes in developing countries: a systematic review. Telemed J E Health 2014;20:75-82.

24. Lewis T, Synowiec C, Lagomarsino G, et al. E-health in low- and middle-income countries: findings from the Center for Health Market Innovations. Bull World Health Organ 2012;90:332-40.

25. Piette JD, Lun KC, Moura LA et al. Impacts of e-health on the outcomes of care in low- and middle-income countries: where do we go from here? Bull World Health Organ 2012;90:365-72.

26. Scott RE, Mars M. Principles and framework for ehealth strategy development. J Med Internet Res 2013;15:e155.

27. Khoja S, Durrani H, Scott RE, et al. Conceptual framework for development of comprehensive e-health evaluation tool. Telemed $J$ E Health 2013;19:48-53

28. Khoja S, Durrani H. Introduction to $m$ Health-focused issue on evidence-based eHealth adoption and application: AME Publications, 2017.

29. Fraser $\mathrm{H}$, Bailey $\mathrm{C}$, Sinha $\mathrm{C}$, et al. Call to action on global eHealth evaluation: consensus statement of the WHO Global eHealth Evaluation Meeting, Bellagio, September 2011. Bellagio, Italy: Bellagio eHealth Evaluation Group, 2011.

30. Guadagnoli E, McNeil BJ. Outcomes research: hope for the future or the latest rage? Inquiry 1994:14-24.

31. Hepworth J. Debate. Evaluation in health outcomes research: linking theories, methodologies and practice in health promotion. Health Promot Int 1997;12:233-8.

32. Moher D, Liberati A, Tetzlaff J, et al. Preferred reporting items for systematic reviews and meta-analyses: the prisma statement. PLoS Med 2009;6:e1000097.

33. Caroline Perrin LH, Geissbuhler A. A systematic review to identify proxy-indicators to quantify the impact of eHealth tools on maternal and neonatal health outcomes in low and middle-income countries - including Delphi consensus. Prospero 2018 https:// www.crd.york.ac.uk/prospero/display_record.php?RecordID= 27351

34. Robinson KA, Chou $\mathrm{R}$, Berkman ND, et al. Twelve recommendations for integrating existing systematic reviews into new reviews: EPC guidance. J Clin Epidemiol 2016;70:38-44.

35. Higgins JPT, Altman DG, Gotzsche PC, et al. The Cochrane Collaboration's tool for assessing risk of bias in randomised trials. BMJ 2011;343:d5928.

36. Sterne J, Higgins J, Reeves B, et al. A Cochrane risk of bias assessment tool: For non-randomized studies of interventions (ROBINS-I). BMJ.

37. Whiting P, Savović J, Higgins JPT, et al. ROBIS: a new tool to assess risk of bias in systematic reviews was developed. $J$ Clin Epidemiol 2016;69:225-34. 
38. Guyatt GH, Oxman AD, Vist GE, et al. GRADE: an emerging consensus on rating quality of evidence and strength of recommendations. BMJ 2008.

39. Balshem $\mathrm{H}$, Helfand $\mathrm{M}$, Schünemann $\mathrm{HJ}$, et al. GRADE quidelines: 3. Rating the quality of evidence. J Clin Epidemiol 2011;64:401-6.

40. Guyatt G, Oxman AD, Akl EA, et al. GRADE guidelines: 1. Introduction-GRADE evidence profiles and summary of findings tables. J Clin Epidemiol 2011;64:383-94.

41. Conde-Agudelo A, Rosas-Bermúdez A, Kafury-Goeta AC. Birth Spacing and Risk of Adverse Perinatal Outcomes. JAMA 2006;295:1809-23.

42. Blencowe $\mathrm{H}$, Cousens $\mathrm{S}$, Modell $\mathrm{B}$, et al. Folic acid to reduce neonatal mortality from neural tube disorders. Int $\mathrm{J}$ Epidemiol 2010;39(Suppl 1):i110-21.

43. Haider BA, Bhutta ZA. Multiple-micronutrient supplementation for women during pregnancy. The Cochrane Library 2012.

44. Lassi ZS, Mansoor T, Salam RA, et al. Essential pre-pregnancy and pregnancy interventions for improved maternal, newborn and child health. Reprod Health 2014;11:S2

45. Wardlaw TM. Low birthweight: country, regional and global estimates: UNICEF WHO, 2004.

46. Susser M. Prenatal nutrition, birthweight, and psychological development: an overview of experiments, quasi-experiments, and natural experiments in the past decade. Am J Clin Nutr 1981;34:784-803.

47. Kramer MS. Effects of energy and protein intakes on pregnancy outcome: an overview of the research evidence from controlled clinical trials. Am J Clin Nutr 1993:58:627-35.

48. Prentice AM, Cole TJ, Foord FA, et al. Increased birthweight after prenatal dietary supplementation of rural African women. Am J Clin Nutr 1987:46:912-25.

49. Kusin JA, Kardjati S, Renqvist UH. Chronic undernutrition in pregnancy and lactation. Proc Nutr Soc 1993;52:19-28.

50. Ceesay SM, Prentice AM, Cole TJ, et al. Effects on birth weight and perinatal mortality of maternal dietary supplements in rural gambia: 5 year randomised controlled trial. BMJ 1997;315:786-90.

51. Bhutta ZA, Das JK, Bahl R, et al. Can available interventions end preventable deaths in mothers, newborn babies, and stillbirths, and at what cost? The Lancet 2014;384:347-70.

52. Goldenberg RL, McClure EM, Saleem S, et al. Infection-related stillbirths. The Lancet 2010;375:1482-90.

53. Blencowe H, Cousens S, Kamb M, et al. Lives Saved Tool supplement detection and treatment of syphilis in pregnancy to reduce syphilis related stillbirths and neonatal mortality. BMC Public Health 2011;11:11:1.

54. Ishaque S, Yakoob MY, Imdad A, et al. Effectiveness of interventions to screen and manage infections during pregnancy on reducing stillbirths: a review. BMC Public Health 2011;11(Suppl 3):S3

55. Radeva-Petrova D, Kayentao K, ter Kuile FO, et al. Drugs for preventing malaria in pregnant women in endemic areas: any drug regimen versus placebo or no treatment. Cochrane Database Syst Rev 2014;9.

56. Siegfried N, Uthman OA, Rutherford GW. Optimal time for initiation of antiretroviral therapy in asymptomatic, HIV-infected, treatmentnaive adults. Cochrane Database Syst Rev 2010:CD008272.

57. Kitahata MM, Gange SJ, Abraham AG, et al. Effect of early versus deferred antiretroviral therapy for HIV on survival. N Engl J Med 2009;360:1815-26.

58. Pottie K, Medu O, Welch V, et al. Effect of rapid HIV testing on HIV incidence and services in populations at high risk for HIV exposure: an equity-focused systematic review. BMJ Open 2014;4:e006859.

59. Miro JM, Manzardo C, Mussini C, et al. Survival outcomes and effect of early vs. deferred cART among HIV-infected patients diagnosed at the time of an AIDS-defining event: a cohort analysis. PLoS One 2011;6:e26009.

60. Siegfried N, van der Merwe L, Brocklehurst P, et al. Antiretrovirals for reducing the risk of mother-to-child transmission of HIV infection. The Cochrane Library 2011.

61. Horvath T, Azman H, Kennedy GE, et al. Mobile phone text messaging for promoting adherence to antiretroviral therapy in patients with HIV infection. Cochrane Database Syst Rev 2012;376.

62. Wu G, Zaman MH. Low-cost tools for diagnosing and monitoring HIV infection in low-resource settings. Bull World Health Organ 2012;90:914-20.

63. King JF, Flenady V, Papatsonis D, et al. Calcium channel blockers for inhibiting preterm labour. The Cochrane Library 2014.

64. Roberts D, Dalziel S. Antenatal corticosteroids for accelerating fetal lung maturation for women at risk of preterm birth (Review). Cochrane Database Syst Rev 2006;19.

65. Crowther CA, McKinlay CJ, Middleton P, et al. Repeat doses of prenatal corticosteroids for women at risk of preterm birth for improving neonatal health outcomes. Cochrane Database Syst Rev 2015;24:CD003935.

66. Say L, Chou D, Gemmill A, et al. Global causes of maternal death: a WHO systematic analysis. Lancet Glob Health 2014;2:e323-33.

67. Lopez-Mendez MA, Martinez-Gaytan V, Cortes-Flores R, et al. Doppler ultrasound evaluation in preeclampsia. BMC Res Notes 2013;6:477.

68. Cnossen JS, Morris RK, ter Riet G, et al. Use of uterine artery Doppler ultrasonography to predict pre-eclampsia and intrauterine growth restriction: a systematic review and bivariable metaanalysis. Can Med Assoc J 2008;178:701-11.

69. Roberts JM, Escudero C. The placenta in preeclampsia. Pregnancy Hypertens 2012;2:72-83.

70. Imdad A, Bhutta ZA. Effects of calcium supplementation during pregnancy on maternal, fetal and birth outcomes. Paediatr Perinat Epidemiol 2012;26(8):138-52.

71. Ortega RM, Martínez RM, López-Sobaler AM, et al. Influence of calcium intake on gestational hypertension. Ann Nutr Metab 1999;43:37-46.

72. Imdad A, Jabeen A, Bhutta ZA. Role of calcium supplementation during pregnancy in reducing risk of developing gestational hypertensive disorders: a meta-analysis of studies from developing countries. BMC Public Health 2011:11:11(3):1.

73. Hofmeyr GJ, Lawrie TA, Atallah AN, et al. Calcium supplementation during pregnancy for preventing hypertensive disorders and related problems. Cochrane Database Syst Rev 2014;3:CD001059

74. Duley L, Henderson-Smart D, Meher S, et al. Antiplatelet agents for preventing pre-eclampsia and its complications (Review). Cochrane Database Syst Rev 2007;2:121.

75. Okereke $\mathrm{E}$, Ahonsi B, Tukur J, et al. Benefits of using magnesium sulphate (MgSO4) for eclampsia management and maternal mortality reduction: lessons from Kano State in Northern Nigeria. BMC Res Notes 2012;5:421.

76. Duley L. Evidence and practice: the magnesium sulphate story. Best Pract Res Clin Obstet Gynaecol 2005;19:57-74.

77. Altman D, Carroli G, Duley L, et al. Do women with preeclampsia, and their babies, benefit from magnesium sulphate? The Magpie Trial: a randomised placebo-controlled trial. Lancet 2002;359:1877-90.

78. Duley L, Gülmezoglu AM, Henderson-Smart DJ. Magnesium sulphate and other anticonvulsants for women with pre-eclampsia. The Cochrane Library 2003.

79. Tukur J, Ahonsi B, Mohammed Ishaku S, Ishaku SM, et al. Maternal and fetal outcomes after introduction of magnesium sulphate for treatment of preeclampsia and eclampsia in selected secondary facilities: a low-cost intervention. Matern Child Health $J$ 2013;17:1191-8.

80. Shamsuddin L, Nahar K, Nasrin B, et al. Use of parenteral magnesium sulphate in eclampsia and severe pre-eclampsia cases in a rural set up of Bangladesh. 2005.

81. WHO. WHO recommendation on use of magnesium sulfate to prevent and treat eclampsia, where the full regimen cannot be administered. Geneva: World Health Organization: WHO Reproductive Health Library, 2011.

82. Oringanje $\mathrm{C}$, Meremikwu MM, Eko $\mathrm{H}$, et al. Interventions for preventing unintended pregnancies among adolescents. Cochrane Database Syst Rev 2016;27.

83. Ngo TD, Park MH, Shakur H, et al. Comparative effectiveness, safety and acceptability of medical abortion at home and in a clinic: a systematic review. Bull World Health Organ 2011;89:360-70.

84. Creinin MD. Medical abortion regimens: historical context and overview. Am J Obstet Gynecol 2000;183:S3-S9.

85. Blencowe $\mathrm{H}$, Cousens $\mathrm{S}$, Mullany LC, et al. Clean birth and postnatal care practices to reduce neonatal deaths from sepsis and tetanus: a systematic review and Delphi estimation of mortality effect. BMC Public Health 2011;11:11.

86. Hofmeyr GJ, Mshweshwe NT, Gülmezoglu AM. Cochrane Pregnancy and Childbirth Group. Controlled cord traction for the third stage of labour. Cochrane Database Syst Rev 2015;107.

87. WHO. WHO recommendatioins for the prevention and treatment or postpartum haemorrhage: evidence base. 2012.

88. Begley CM, Gyte GM, Devane D, et al. Active versus expectant management for women in the third stage of labour. Cochrane Database Syst Rev 2015;6:CD007412

89. Winikoff B, Dabash R, Durocher J, et al. Treatment of post-partum haemorrhage with sublingual misoprostol versus oxytocin in women not exposed to oxytocin during labour: a double-blind, randomised, non-inferiority trial. The Lancet 2010;375:210-6.

90. Ö T, Hofmeyr GJ, Gülmezoglu AM. Prostaglandins for preventing postpartum haemorrhage. Cochrane Database Syst Rev 2012;8. 
91. Akhter S, Begum MR, Kabir Z, et al. Use of a condom to control massive postpartum hemorrhage. MedGenMed 2003;5:38.

92. Tindell K, Garfinkel R, Abu-Haydar E, et al. Uterine balloon tamponade for the treatment of postpartum haemorrhage in resource-poor settings: a systematic review. BJOG 2013;120:5-14.

93. Burke TF, Ahn R, Nelson BD, et al. A postpartum haemorrhage package with condom uterine balloon tamponade: a prospective multi-centre case series in Kenya, Sierra Leone, Senegal, and Nepal. BJOG 2016;123.

94. Aderoba AK, Olagbuji BN, Akintan AL, et al. Condom-catheter tamponade for the treatment of postpartum haemorrhage and factors associated with success: a prospective observational study. BJOG 2017;124.

95. Moore ER, Anderson GC, Bergman N, et al. Early skin-to-skin contact for mothers and their healthy newborn infants. Cochrane Database Syst Rev 2012;5.

96. Debes AK, Kohli A, Walker N, et al. Time to initiation of breastfeeding and neonatal mortality and morbidity: a systematic review. BMC Public Health 2013;13:1.

97. WHO. WHO recommendations on postnatal care of the mother and newborn: World Health Organization, 2014.

98. Bergström A, Byaruhanga R, Okong P. The impact of newborn bathing on the prevalence of neonatal hypothermia in Uganda: a randomized, controlled trial. Acta Paediatr 2005;94:1462-7.

99. Sinha A, Sazawal S, Pradhan A, et al. Chlorhexidine skin or cord care for prevention of mortality and infections in neonates. Cochrane Database Syst Rev 2015;379.

100. Puckett RM, Offringa M. Prophylactic vitamin $K$ for vitamin $K$ deficiency bleeding in neonates. Cochrane Database Syst Rev 2000;33:CD002776.

101. Wall SN, Lee AC, Niermeyer S, et al. Neonatal resuscitation in lowresource settings: what, who, and how to overcome challenges to scale up? Int J Gynaecol Obstet 2009;107:S47-64.

102. Lee AC, Cousens S, Wall SN, et al. Neonatal resuscitation and immediate newborn assessment and stimulation for the prevention of neonatal deaths: a systematic review, meta-analysis and Delphi estimation of mortality effect. BMC Public Health 2011;11:11.

103. Conde-Agudelo A, Díaz-Rossello JL. Kangaroo mother care to reduce morbidity and mortality in low birthweight infants. Cochrane Database Syst Rev 2014:CD002771.
104. Young Infants Clinical Signs Study Group. Clinical signs that predict severe illness in children under age 2 months: a multicentre study. Lancet 2008;371:135-42.

105. Borkum E, Sivasankaran A, Sridharan S, et al. Evaluation of the Information and Communication Technology (ICT) Continuum of Care Services (CCS): Intervention in Bihar: Mathematica Policy Research, 2015.

106. Edhi MM, Aslam HM, Naqvi Z, et al. "Post partum hemorrhage: causes and management". BMC Res Notes 2013;6:236

107. Koblinsky MA. Beyond maternal mortality-magnitude, interrelationship, and consequences of women's health, pregnancyrelated complications and nutritional status on pregnancy outcomes. Int J Gynaecol Obstet 1995;48:S21-32.

108. Biswas A, Anderson R, Doraiswamy $\mathrm{S}$, et al. Timely referral saves the lives of mothers and newborns: Midwifery led continuum of care in marginalized teagarden communities - a qualitative case study in Bangladesh. F1000Res 2018;7:365.

109. WOMAN Trial Collaborators. Effect of early tranexamic acid administration on mortality, hysterectomy, and other morbidities in women with post-partum haemorrhage (WOMAN): an international, randomised, double-blind, placebo-controlled trial. Lancet 2017;389:2105-16

110. Demicheli V, Barale A, Rivetti A. Cochrane Pregnancy and Childbirth Group. Vaccines for women for preventing neonatal tetanus. Cochrane Database Syst Rev 2015;58.

111. Chamberlain C, O'Mara-Eves A, Oliver S, et al. Psychosocial interventions for supporting women to stop smoking in pregnancy. Cochrane Database Syst Rev 2013:CD001055.

112. Hofmeyr GJ, Kulier R, West HM. Cochrane Pregnancy and Childbirth Group. External cephalic version for breech presentation at term. Cochrane Database Syst Rev 2015;91.

113. Hussain AA, Yakoob MY, Imdad A, et al. Elective induction for pregnancies at or beyond 41 weeks of gestation and its impact on stillbirths: a systematic review with meta-analysis. BMC Public Health 2011;11:11.

114. Cherniak W, Anguyo G, Meaney C, et al. Effectiveness of advertising availability of prenatal ultrasound on uptake of antenatal care in rural Uganda: A cluster randomized trial. PLoS One 2017;12:e0175440. 